\title{
Factors Associated with Maternal-infant Attachment One
}

\section{Month Postnatally}

\author{
Sahar A Rizk*
}

\begin{abstract}
Background: maternal-infant attachment (MIA) or bonding is a vital process which has tremendous implications for both mother and infant and is affected by many factors. Identifying such factors enable healthcare staff to detect those mothers with bonding difficulties and in need of individualized attention during their postpartum period. Objectives: To identify factors associated with MIA one month after child birth. Methods: We executed a cross-sectional descriptive study that included a convenience sample of 150 postnatal women attending El Shatby Maternity University hospital in Alexandria, free of any medical condition and willing to participate in the study. A structured validated interview questionnaire was used to collect socio-demographic characteristics, reproductive history and the MIA Scale. Results: A month after delivery, 48(32\%), 31(20.7\%) and 71(47.3\%) of mothers respectively had negative, unclear and positive MIA. Positive MIA was significantly more among educated $(50.8 \%)$, employed $(52.7 \%)$, socially supported $(61.1 \%)$, primigravidous $(60.7 \%)$ and primiparous $(58 \%)$ mothers having urban residency $(53 \%)$, full-term $(54.2 \%)$ breast fed $(61.3 \%)$ boy $(63.5 \%)$, planned pregnancy $(58.4 \%)$ and no history of abortion $(52.7 \%)(p<0.05)$. Conclusion: Bonding is significantly associated with maternal and infant factors. Maternal factors include women education, occupation, residence, social support, gravidity, parity, abortion and pregnancy planning status, whereas infant related factors included infant gender, feeding pattern, maturity and type of care received.
\end{abstract}

Key words: Mother-infant attachment, bonding, postnatal period.

\section{INTRODUCTION}

Maternal-infant (MIA) attachment or bonding is a natural phenomenon that is described as a gradual process of emotional involvement. ${ }^{(1)}$ MIA refers to the affective dimension in the mother-infant relationship.(2) It is the development of the reciprocal relationship between the mother and her infant.
After birth, MIA is assumed to be an adaptive mechanism that is biologically driven, mainly by oxytocin.(3) The attachment process has tremendous implications for both mother and infant and is also encouraged by physical contact between them. The quality of this attachment can be influenced by several maternal and infant related factors. The infant

\footnotetext{
${ }^{*}$ Obstetric and Gynecologic Nursing Department, Faculty of Nursing, Alexandria University
} 
factors are prematurity, physical pathology and irritable temperament while the maternal ones include mother's style of attachment, support network and development of physical illness. ${ }^{(4)}$ Attachment is also linked to mothers' previous experiences and early postnatal mood; for example, depressed mothers have worse attachment, compared to mothers with elevated mood after delivery. ${ }^{(5)}$

The first minutes, hours and days following delivery represent a very sensitive and period critical for bonding during which the baby and the mother become intimately involved with each other through behaviors and stimuli that provoke further interactions and stimulate more specific infant social skills likely to emerge.(6) The mother-infant bond is enhanced by early and continuous contact. ${ }^{(7)}$

Attachment usually develops through three phases. The first is "pre-attachment phase", where babies orient and signal to people without discrimination of figures. Soon thereafter, during the second phase "attachment-in-the-making", they begin to show discrimination in directing their various attachment behaviors to different figures, and these figures may also differ in how readily they can terminate an attachment behavior, such as crying. By the end of the first year of life, most babies usually reach the third phase; a "clear-cut attachment" to one or more specific caregiver. They not only show simple preference of these figures over others, but also actively seek and maintain proximity and contact with their attachment figures and react with distress to separation. ${ }^{(8)}$ Although a clearcut attachment has been formed at the end of the first year, attachment security can change during infancy, childhood, and adolescence when the family environment changes. ${ }^{(9)}$

According to Bowlby's proposed internal working models of attachment theory, attachment is an interdisciplinary study encompassing the fields of psychological evolutionary, and ethological theory. This theory states that infants become attached to 
individuals who are sensitive and responsive in social interactions with them, and who remain as consistent caregivers for some months to two years of age; a matter which is known as sensitive responsiveness. (10) When an infant begins to crawl and walk they begin to use attachment figures (familiar people) as a secure base to explore from and return to. Caregivers' responses lead to the development of patterns of attachment. These, in turn, lead to internal working models which will guide the individual's perceptions, emotions, thoughts and expectations in later relationships. ${ }^{(11)}$

There are controversial empirical results regarding the presence of MIA after delivery. Several authors agreed that attachment does not immediately establish after childbirth, and intensifies gradually with time. ${ }^{(1,11,12)}$ They rely on the fact that better attachment can be observed some months later rather than soon after childbirth. Other studies elaborated that bonding develops after birth and continues to develop beyond the early postnatal period. ${ }^{(11,12)}$
Researchers and health professionals have pointed out the importance of studying attachment among parents, especially from mothers' perspective not only from infant one. Mothers' emotional involvement is a decisive element to the quality of care and interaction provided by them. It is of critical importance for establishing a successful relationship and mutual understanding between caregiver and infant. ${ }^{(13,14)}$ The determinant factors associated with infant attachment can influence infant development as well. Identifying such factors enables healthcare staff to detect those mothers experiencing bonding difficulties and in need of individualized attention during postpartum period. Accordingly, this study aimed to identify factors associated with maternal-infant attachment one month after childbirth.

\section{SUBJECTS AND METHODS}

Study design and setting: We followed an exploratory descriptive cross-sectional research design, where a convenience sample of 150 postnatal women (up to one month after 
delivery) attending the family planning and covered data about the socio-demographic gynecological clinics at El-Shatby University characteristics and reproductive history of Hospital in Alexandria were invited to postnatal women, such as age, educational participate in the study. This setting was of level, occupation, residence, gravidity and particular interest because of the satisfactory parity. whereas fetal variables included data number of attendants. Nevertheless, the relevant to general characteristics of the number of participants was limited because bonding evolves soon after birth and continues Tool II: Mother-to-Infant Attachment Scale to develop beyond the early postnatal period, $(\mathrm{MIAS})^{(15)}$; that was originally developed by and so the best period for data collection was Bhakoo et al to measure mothers' one month postnatally. ${ }^{(12)}$ The inclusion criteria for the study subjects were:

affectionate attachment to their infants. This scale was adapted, modified and translated

- Being free of any medical or by the researcher to suit the Egyptian gynecological diseases.

culture. It consists of 15 statements; 8

- Willing to participate in the study.

statements reflected positive affectionate

Data Collection Tools: Two tools have been attachment and 7 for the negative one. used: Tool I: A structured pre-coded Subjects' responses to each item varied interview questionnaire was used for from "not at all"; scoring zero to "very much" collection of the socio-demographic data scoring 2. Subjects' total scores ranged and reproductive history. This was between $0-30$ and hence categorized as developed by the researcher after extensive follows:

review of relevant and recent literature, and

Positive attachment $<10$ includes two parts describing maternal as Unclear attachment $\quad 10-20$ well as infant variables. Maternal variables Negative attachment $>20$ 
Methods: This study was approved by the ethical committee of the faculty of nursingAlexandria University and the responsible authorities of the study settings. A written informed consent was provided by all participants prior to enrollment, after explaining the aim and concerns of the research. Tools were tested for content validity by a jury of 5 experts in the related field.

Tool II reliability was accomplished by the split half reliability technique. The instrument showed reasonable score of internal consistency (Cronbach alpha= 0.620$)$.

A pilot study was carried out on 15 of postnatal women and thus served to evaluate clarity, applicability, time of administration for questionnaire and possible obstacles and problems that may arise during the actual work. Based on the pilot results; there was no need for amendment in the developed tools. However, subjects of the pilot were not included in the main study sample.
Data collection covered a period of four months; from the beginning of January to the mid of April 2011. Data sheets were coded under strict anonymity respecting the confidentiality of participants' information.

Statistical analysis was performed using SPSS version 16.0 for windows and employing appropriate statistical tests; percentage, mean, standard deviations, and Chi Square test. The significance level calculated for a particular Chi-square statistic is less than or equal to 0.05 ( $P$ value $\leq 0.05)$.

\section{RESULTS}

Analysis of the socio-demographic characteristics of postnatal women revealed that about two-thirds (68\%) of the study subjects aged 30 years or older and about $64 \%$ were covered by a social support system. approximately one half of the surveyed mothers (43.3\%) had a secondary school education or higher and almost equal proportions of housewives and employees were presented $(49.3 \%$ and $45.3 \%$ respectively). About three-fifths (59.3\%) did 
perceive their family income as adequate and their infants were much affectionate (92\%) to the majority (89.3\%) were urban residents. them and when their infants were out of their Considering the reproductive history of sight they always worry that something may postnatal women, about one-third of the study happen to them $(89.3 \%)$. Meanwhile, equal subjects were either primigravida (36.7\%) or percentages of mothers were proud of their primiparas (31.3\%) and history of abortion was infants $(78.7 \%)$ or perceived that their infants reported by only $26.7 \%$.Almost half $(51.3 \%)$ of $\quad$ had great fortune $(78.7 \%)$. Less than two-thirds them had their last pregnancy been planned of the study subjects $(60 \%)$ believed that their and about $54.7 \%$ had normal delivery. As infants are promising. On the other hand, only regards infant general characteristics, it was minorities felt that they don't like their infants obvious that the majority of infants (87.3\%) (3.3\%), were angry with (5.3\%) or annoyed by were born full-term and bout two-thirds (67.3\%) their infants $(8 \%)$, or were troubled a lot by have received routine care. More than half them (10.70\%). About half $(47.3 \%)$ of the $(56.7 \%)$ of the studied infants were boys while mothers had positive attachment to their infants $10.7 \%$ were twins (boy and girl). Breast-fed at one month postnatally. Negative attachment infants rated $64 \%$ while more than one-tenth was recorded by $32 \%$ of mothers, while only $(12.7 \%)$ were born premature. one-fifth $(20.7 \%)$ of them had unclear Patterns of MIA among postnatal women one attachment. [Table 1 and Figure 1] month postnatally are clarified in (Table 1). The majority of the study subjects reported that 
Table 1: Distribution of postnatal women according to items of maternal-infant Attachment

\begin{tabular}{|c|c|c|c|c|c|c|}
\hline \multirow{2}{*}{ Items of Mother Infant Attachment } & \multicolumn{2}{|c|}{ Very Much } & \multicolumn{2}{|c|}{ Little } & \multicolumn{2}{|c|}{ Not at all } \\
\hline & No & $\%$ & No & $\%$ & No & $\%$ \\
\hline - I feel that I don't like this infant & 5 & 3.3 & 12 & 8.0 & 133 & 88.7 \\
\hline $\begin{array}{l}\text { - I love this infant so much that I cannot bear to } \\
\text { be away from him (her) even for a short time }\end{array}$ & 108 & 72.0 & 8 & 5.3 & 34 & 22.7 \\
\hline - This infant is difficult to bring up & 25 & 16.7 & 56 & 37.3 & 69 & 46 \\
\hline - I am extremely proud of this infant & 118 & 78.7 & 12 & 8.0 & 20 & 13.3 \\
\hline $\begin{array}{l}\text { - When this infant is out of my sight I always } \\
\text { worry that something may happen to him (her) }\end{array}$ & 134 & 89.3 & 4 & 2.7 & 12 & 8.0 \\
\hline - I am annoyed by this infant & 12 & 8.0 & 20 & 13.3 & 118 & 78.7 \\
\hline - It seems that this infant has great fortune & 118 & 78.7 & 24 & 16.0 & 8 & 5.3 \\
\hline - It seems that this infant obeys me & 61 & 40.7 & 61 & 40.7 & 28 & 18.6 \\
\hline - This infant has troubled me a lot & 16 & 10.7 & 28 & 18.6 & 106 & 70.7 \\
\hline - This infant is of my expectation & 49 & 32.7 & 69 & 46.0 & 32 & 21.3 \\
\hline - This infant has increased our difficulties & 49 & 32.7 & 24 & 16.0 & 77 & 51.3 \\
\hline - I feel angry with this infant & 8 & 5.3 & 24 & 16.0 & 118 & 78.7 \\
\hline - This infant is much affectionate to me & 138 & 92.0 & 8 & 5.3 & 4 & 2.7 \\
\hline - This infant seems to be promising & 90 & 60.0 & 56 & 37.3 & 4 & 2.7 \\
\hline - This infant has a lot of patience & 45 & 30.0 & 47 & 31.3 & 58 & 38.7 \\
\hline
\end{tabular}

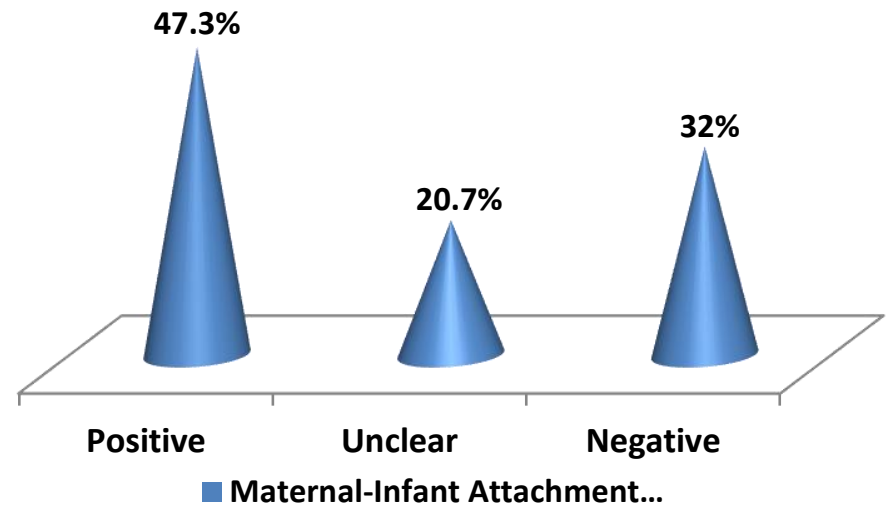

Figure 1: Postnatal women according to their total scores on Maternal-Infant Attachment Scale (MIAS) 
Table2: When we investigated relationship compared to $52.4 \%$ illiterate, $35.3 \%$ between MIA among postnatal women and housewives, 75\% rural residents, and $42.7 \%$ their socio-demographic characteristics, we women not subjected to social supportive observed that positive attachment was more system that mainly showed negative encountered among highly educated mothers attachment. Accordingly, MIA was found (50.7\%), employed (52.7\%), those living in significantly related to the educational level, urban residence $(53 \%)$, and mothers covered occupation, residency and social supportive by a social support system $(61.1 \%)$, if $\quad$ system $(P<0.05)$.

Table 2: Relationship between maternal-infant attachment among postnatal women and their socio demographic characteristics

\begin{tabular}{|c|c|c|c|c|c|c|c|c|c|}
\hline \multicolumn{10}{|c|}{ Maternal Infant Attachment } \\
\hline \multirow[t]{2}{*}{ General characteristic } & \multicolumn{2}{|c|}{$\begin{array}{c}\text { Positive } \\
(n=71)\end{array}$} & \multicolumn{2}{|c|}{$\begin{array}{l}\text { Unclear } \\
(n=31)\end{array}$} & \multicolumn{2}{|c|}{$\begin{array}{c}\text { Negative } \\
(n=48)\end{array}$} & \multicolumn{2}{|c|}{$\begin{array}{c}\text { Total } \\
(n=150)\end{array}$} & \multirow[t]{2}{*}{$\begin{array}{c}\mathrm{X}^{2} / \mathrm{FET} \\
(\boldsymbol{P} \text {-value })\end{array}$} \\
\hline & No & $\%$ & No & $\%$ & No. & $\%$ & No. & $\%$ & \\
\hline \multicolumn{10}{|l|}{ Age (years): } \\
\hline$<30$ & 25 & 52.1 & 6 & 12.5 & 17 & 35.4 & 48 & 100 & 2.87 \\
\hline$>30$ & 46 & 45.1 & 25 & 24.5 & 31 & 30.4 & 102 & 100 & $(0.238)$ \\
\hline \multicolumn{10}{|l|}{ Level of education: } \\
\hline Illiterate/read \& write & 6 & 28.6 & 4 & 19.0 & 11 & 52.4 & 21 & 100 & \\
\hline$<$ Secondary education & 32 & 50.0 & 7 & 10.9 & 25 & 39.1 & 64 & 100 & 15.97 \\
\hline$\geq$ Secondary education & 33 & 50.8 & 20 & 30.8 & 12 & 18.4 & 65 & 100 & $(0.003)^{\star}$ \\
\hline \multicolumn{10}{|l|}{ Occcupation: } \\
\hline Housewife & 32 & 47.1 & 12 & 17.6 & 24 & 35.3 & 68 & 100 & \\
\hline Worker & 0 & 0.0 & 8 & 100.0 & 0 & 0.0 & 8 & 100 & 32.90 \\
\hline Employee & 39 & 52.7 & 11 & 14.9 & 24 & 32.4 & 74 & 100 & $(0.000)^{*}$ \\
\hline \multicolumn{10}{|l|}{ Perceived income: } \\
\hline Adequate & 45 & 51.1 & 20 & 22.7 & 23 & 26.2 & 88 & 100 & 2.56 \\
\hline Inadequate & 26 & 42.0 & 11 & 17.7 & 25 & 40.3 & 62 & 100 & $(0.278)$ \\
\hline \multicolumn{10}{|l|}{ Residence: } \\
\hline Urban & 71 & 53.0 & 27 & 20.1 & 36 & 26.9 & 134 & 100 & 18.99 \\
\hline Rural & 0 & 0.0 & 4 & 25.0 & 12 & 75.0 & 16 & 100 & $(0.000)^{*}$ \\
\hline \multicolumn{10}{|l|}{ Social support system: } \\
\hline Not Present & 38 & 39.6 & 17 & 17.7 & 41 & 42.7 & 96 & 100 & 14.07 \\
\hline Present & 33 & 61.1 & 14 & 25.9 & 7 & 13.0 & 54 & 100 & $(0.001)$ * \\
\hline
\end{tabular}


Table 3: The study of MIA among postnatal MIA was evident among all postnatal women women in relation to mother's reproductive who have had one abortion. More than twohistory revealed that, positive attachment was a fifths of them were either multigravida (48.7\%) common feature among women who were or multipara (53.7\%) while only $38.4 \%$ had either primigravida $(60.7 \%)$ or primipara unplanned pregnancy. MIC was found (58.1\%), who didn't experience abortion before significantly related to gravidity, parity, abortion (52.7\%), and those having their pregnancy and pregnancy planning status $(P=0.05)$. been planned (58.4\%). Meanwhile, negative

Table 3: Relationship between maternal-infant attachment among postnatal women and their reproductive history

\begin{tabular}{|c|c|c|c|c|c|c|c|c|c|}
\hline \multirow{3}{*}{ Reproductive History } & \multicolumn{8}{|c|}{ Maternal Infant Attachment } & \multirow{3}{*}{$\begin{array}{c}\mathbf{X}^{2} / \mathbf{F E T} \\
(P \text {-value })\end{array}$} \\
\hline & \multicolumn{2}{|c|}{$\begin{array}{c}\text { Positive } \\
(n=71)\end{array}$} & \multicolumn{2}{|c|}{$\begin{array}{c}\text { Unclear } \\
(n=31)\end{array}$} & \multicolumn{2}{|c|}{$\begin{array}{c}\text { Negative } \\
(n=48)\end{array}$} & \multicolumn{2}{|c|}{$\begin{array}{l}\text { Total } \\
(n=150)\end{array}$} & \\
\hline & no & $\%$ & no & $\%$ & no & $\%$ & no & $\%$ & \\
\hline \multicolumn{10}{|l|}{ Gravidity: } \\
\hline 1 & 34 & 60.7 & 5 & 8.9 & 17 & 30.4 & 56 & 100 & \multirow{3}{*}{$\begin{array}{l}17.26 \\
(0.002) \text { * }\end{array}$} \\
\hline $2-3$ & 12 & 30.8 & 8 & 20.5 & 19 & 48.7 & 39 & 100 & \\
\hline$>3$ & 25 & 45.5 & 18 & 32.7 & 12 & 21.8 & 55 & 100 & \\
\hline \multicolumn{10}{|l|}{ Parity : } \\
\hline 1 & 36 & 58.0 & 5 & 8.1 & 21 & 33.9 & 62 & 100 & \multirow{3}{*}{$\begin{array}{c}29.98 \\
(0.000) \text { * }\end{array}$} \\
\hline $2-3$ & 12 & 29.2 & 7 & 17.1 & 22 & 53.7 & 41 & 100 & \\
\hline$>3$ & 23 & 49.0 & 19 & 40.4 & 5 & 10.6 & 47 & 100 & \\
\hline \multicolumn{10}{|l|}{ Type of delivery: } \\
\hline Normal & 39 & 47.6 & 15 & 18.3 & 28 & 34.1 & 82 & 100 & \multirow{3}{*}{$\begin{array}{c}0.75 \\
(0.685)\end{array}$} \\
\hline Instrumental & 32 & 47.1 & 16 & 23.5 & 20 & 29.4 & 68 & 100 & \\
\hline \multicolumn{9}{|l|}{ No of abortions: } & \\
\hline 0 & 58 & 52.7 & 20 & 18.2 & 32 & 29.1 & 110 & 100 & \multirow{4}{*}{$\begin{array}{c}22.00 \\
(0.000) \text { * }\end{array}$} \\
\hline$<2$ & 0 & 0.0 & 0 & 0.0 & 8 & 100.0 & 8 & 100 & \\
\hline$>2$ & 13 & 40.6 & 11 & 34.4 & 8 & 25.0 & 32 & 100 & \\
\hline \multicolumn{9}{|l|}{ Pregnancy planning status: } & \\
\hline Planned & 45 & 58.4 & 12 & 15.6 & 20 & 26.0 & 77 & 100 & 7.90 \\
\hline Unplanned & 26 & 35.6 & 19 & 26.0 & 28 & 38.4 & 73 & 100 & $(0.019)$ * \\
\hline
\end{tabular}

Table 4: addressed the relationship between characteristics of their infants. Positive MIA among postnatal women and general attachment was demonstrated by almost 
two thirds of postnatal women; either their received routine care (53.5\%). Meanwhile, infants were boys $(63.5 \%)$ or receiving negative MIA was associated with postnatal breast feeding (61.4\%), whereas mothers women whose infants were premature who had negative attachment were those (68.4\%) or did receive medical care $(51 \%)$. having girls $(51 \%)$ or bottle-fed infants We can state thus a statistically significant (50\%). Positive MIA was also obvious relationship between MIA and infant gender, among postnatal women whose infants feeding pattern, type of care received, and were born full-term $(54.2 \%)$ or have infant maturity $(P<0.01)$.

Table 4: Relationship between postnatal women by maternal-infant attachment scale and their general characteristics of the infant

\begin{tabular}{|c|c|c|c|c|c|c|c|c|c|}
\hline \multirow{3}{*}{$\begin{array}{c}\text { General } \\
\text { characteristics } \\
\text { of the infant }\end{array}$} & \multicolumn{6}{|c|}{ Maternal infant attachment } & \multirow{2}{*}{\multicolumn{2}{|c|}{$\begin{array}{c}\text { Total } \\
(n=150)\end{array}$}} & \multirow{3}{*}{$\begin{array}{c}\mathbf{X}^{2} / \mathbf{F E T} \\
(P \text {-value })\end{array}$} \\
\hline & \multicolumn{2}{|c|}{$\begin{array}{c}\text { Positive } \\
(\mathrm{n}=71)\end{array}$} & \multicolumn{2}{|c|}{$\begin{array}{l}\text { Unclear } \\
(n=31)\end{array}$} & \multicolumn{2}{|c|}{$\begin{array}{c}\text { Negative } \\
(n=48)\end{array}$} & & & \\
\hline & no & $\%$ & no & $\%$ & no & $\%$ & no & $\%$ & \\
\hline \multicolumn{10}{|l|}{ Gender } \\
\hline Boy & 54 & 63.5 & 12 & 14.1 & 19 & 22.4 & 85 & 100 & \multirow{3}{*}{$\begin{array}{l}20.42 \\
(0.000)^{\star}\end{array}$} \\
\hline Girl & 12 & 24.5 & 12 & 24.5 & 25 & 51.0 & 49 & 100 & \\
\hline Twins & 5 & 31.2 & 7 & 43.8 & 4 & 25.0 & 16 & 100 & \\
\hline \multicolumn{10}{|l|}{ Feeding Pattern: } \\
\hline Breast feeding & 59 & 61.4 & 16 & 16.7 & 21 & 21.9 & 96 & 100 & \multirow{2}{*}{$\begin{array}{l}14.07 \\
(0.001)^{*}\end{array}$} \\
\hline Bottle feeding & 12 & 22.2 & 15 & 27.9 & 27 & 50.0 & 54 & 100 & \\
\hline \multicolumn{10}{|c|}{ Infants' care received: } \\
\hline Routine care & 54 & 53.5 & 24 & 23.8 & 23 & 22.8 & 101 & 100 & \multirow{2}{*}{$9.68(0.008)^{*}$} \\
\hline Medical care & 17 & 34.7 & 7 & 14.3 & 25 & 51.0 & 49 & 100 & \\
\hline \multicolumn{10}{|l|}{ Maturity } \\
\hline Full-term & 71 & 54.2 & 25 & 19.1 & 35 & 26.7 & 131 & 100 & \multirow[t]{2}{*}{$20.57(0.000)^{*}$} \\
\hline Premature & 0 & 0.0 & 6 & 31.6 & 13 & 68.4 & 19 & 100 & \\
\hline
\end{tabular}

\section{DISCUSSION}

Maternal-infant attachment is of critical between caregiver and infant, which itself importance for establishing a successful provides the basis for the cognitive and relationship and mutual understanding socio-emotional development of the infant. 
Post-partum period is a sensitive stage during which the baby and the mother become intimately involved with each other through behaviors and stimuli that are complementary and provoke further interactions. Identifying the attachment behaviors and parents' emotional involvement is a decisive element to the quality of care and interaction provided by them. Therefore, determining factors associated with infant attachment enables the health care staff to detect those mothers experiencing bonding difficulties and in need of individualized attention during postpartum period.(14)

Regarding responses of postnatal women to items of maternal-infant attachment, the results of the current study revealed that the majority of the study subjects had positive attachment towards their infants one month after delivery. They reported that they were proud of their infants, believed that their infant had great fortune or promising. This finding is consistent with that of Figueiredo et $a^{(16)}$ who indicated that the majority of the mothers and fathers scored strong (very much) positive emotions like 'loving', 'protective' and 'joyful' toward their infants after delivery. Moreover, the study provided evidence that parents usually show a high positive emotional involvement with their newborns as early as the first day after delivery.(16) Taylor et $a^{(12)}$ added that bonding intensifies gradually during the postpartum period. On the other hand, negative maternal-infant attachment was reported by small number of the study subjects. They mentioned that they didn't love their infants, were angry with or annoyed by them, or experienced a lot of trouble with them. Likewise, Figueiredo et $a^{(14)}$ stated that, some mothers and fathers feel 'not at all' or 'at least a little'; 'disappointed', 'resentful', 'dislike', 'aggressive', 'sad', 'neutral' or 'fearful' with their neonates. They added that negative emotional involvement with the newborn 
was absent among the majority of their study sample.

On investigating the maternal infant attachment among postnatal women and their general characteristics, it was obvious that about half of the study subjects who were living in urban residence had positive attachment towered their infant. This is in line with Mickelson et $a{ }^{(17)}$ who found that, attachment was associated with several socio-demographic factors including income, age, and race.

Concerning mother education and employment, our results revealed that positive maternal infant attachment was significantly present among postnatal women who were highly educated and employed. On the other hand, negative attachment was more commonly found among postnatal mothers who were illiterate and housewives. This agreed with several studies, which stated that development of some maternal infant attachment behaviors is significantly associated with mother's education. They also found that most babies of employed mothers are more securely attached to them. ${ }^{(18,19)}$ Alhusen et $a^{(20)}$ also observed that the development of certain pattern of maternal infant behavior was significantly affected by mothers' education. He added that higher education is a predictor of more positive attachment.

The results of the present study also revealed that there is a significant positive relationship between the total score of maternal infant attachment and the existence of a social supportive system. This finding is supported by Cooper et a/21)who mentioned that, providing social support, enhances maternal identity, and facilitates maternal-infant attachment.

No significant relationship was found between maternal infant attachment and total family income. Similarly, Shaw et al., (22) who noted that, mother believes that her baby is the best, most beautiful, and most perfect baby in the world so she feels 
able to care for her baby regardless of her economic status. However, Cooper and coworkers ${ }^{(21)}$ declared that women with low socioeconomic status had less stable attachments. In the present study, we recovered a significant correlation between maternal-infant attachment among postnatal women and their reproductive history. Positive attachment was common among primigravida and primipara who didn't experience abortion before; a finding which also agreed well with that of Feldman et $a{ }^{(23)}$ who reported that primipara started to love her baby since they are pregnant.

Concerning the pregnancy planning status, it was evident in the present work that maternal infant attachment is significantly associated with planned pregnancy. This coincided with results of Alhusen et $a^{(20)}$ who stated that maternalfetal attachment is consistently related to the planning of pregnancy, strength of marital relationship, and gestational age. There was no significant association between maternal infant attachment and type of delivery in our study. This disagreed with Mohamed et al who mentioned that mother who experience cesarean delivery are at a great risk to encounter difficulties in attachment.(19)

In the present work, maternal infant attachment among postnatal women was significantly associated with the general characteristics of their infant. Positive attachment was associated with postnatal women whose infant was mature and have received routine care, whereas negative attachment was associated with postnatal mothers having had premature infant that received special care. These results are in line with previous investigators who mentioned that the period of close contact between mother and infant immediately after birth facilitates establishment of a close bond. Moreover, parental neglect, abuse and even infanticide do occur among infants with poor survival prospects, either due to ill health or detrimental circumstances. ${ }^{(24,25)}$ 
A significant relationship between total score of maternal infant attachment and infant's gender was evident in the current study. Postnatal women who delivered a baby boy were more likely to have positive maternal infant attachment than those having had a baby girl. These findings assured the statement of Mohamed et al that in Egypt, mothers giving birth to baby boy establish more attachment with their babies than who had baby girl. ${ }^{(19)}$ On the other hand, Taylor et al., ${ }^{(12)}$ mentioned that secure, ambivalent and avoidant attachments are about equally common in boys and girls in infancy period. Other studies found that boys were more vulnerable than girls to be at a greater risk of anxious attachment. ${ }^{(14,16)}$

As regards the pattern of feeding, our results conformed those of Gribble et a/(26) that mothers who choose to breastfeed display enhanced sensitivity during early infancy which, in turn, may foster secure attachment.

\section{CONCLUSION AND RECOMMENDATIONS}

Guided by the study results we can elaborate that maternal-infant attachment is significantly associated with several maternal and infant related factors. Those maternal factors are socio-demographic characteristics like education, occupation, residence and social support system and reproductive factors including gravidity, parity, number of abortions and pregnancy planning status. The infant related factors entail infant gender, feeding pattern, maturity and type of care receive after birth. In the light of the study results, it is recommended that maternity nurses should assess postnatal women and their infants for their attachment behaviors and allocate more time to educate them about attachment process and how to accomplish it. Also, further researches are needed to explore different patterns of attachment behaviors and their deviating forms.

\section{REFERENCES}

1. Sroufe L. Attachment and development: A 
prospective, longitudinal study from birth to adulthood. Journal of Attachment Human Development. 2005;7(4):349-67.

2. Troy N. Early contact and maternal attachment among women using public health care facilities. Journal of Applied Nursing Research. 1993;6(4):161-6.

3. Nagasawa M, Okabe $S$, Mogi K, Kikusui T. Oxytocin and mutual communication in mother-infant bonding. Frontiers Human Neuroscience. 2012;6:31.

4. Mills-Koonce W, Gari J, Propper C, Sutton $\mathrm{K}$. Infant and parent factors associated with early maternal sensitivity: A caregiver-attachment systems approach. Journal of Infant Behavior \& Development. 2007;30:114-26.

5. Bretherton I. The origins of attachment theory: John Bowlby and Mary Ainsworth. Journal of Developmental Psychology. 1992;28(5):759-75.

6. Benoit D. Maternal-infant bonding. Journal of Pediatric Child Health. 2004;9(8):5415.

7. Jeannette c, Klaus M. No separation of mother and baby with unlimited opportunity for breastfeeding. Journal of Perinatal Education. 2004;13(2):35-41.

8. Benoit D. Infant-parent attachment: Definition, types, antecedents, measurement and outcome. Journal of Pediatric Child Health. 2004;9(8):541-5.

9. Perez S, Gauvain M. The role of child emotionality in child behavior and maternal instruction on planning tasks. Journal of Social development. 2005;14(2):250-72.

10. Cassidy J, Shaver R. Handbook of attachment: Theory, research, and clinical applications. $2^{\text {nd }}$ ed. New York, NY, US: Guilford Press; 2008;102-27.

11. Bretherton I, Munholl and K. Internal working models in attachment relationships: A construct revisited. In Cassidy J, Shaver PR. Handbook of Attachment: Theory, Research and Clinical Applications. New York: Guilford
Press; 1999;89-114.

12. Taylor A, Atkins R, Kumar R, Glover V. Mother-to-infant bonding scale: links with early maternal mood, Archives of Women's Mental Health. 2005;81:45-51.

13. Janneke $A$, Charlotte $M$, Catharina $H$. Expectant parents: Study protocol of a longitudinal study concerning prenatal (risk) factors and postnatal infant development, parenting, and parent-infant relationships. BMC Pregnancy and Childbirth. 2012;12:46.

14. Figueiredoa B, Costaa R, Pachecoa, Paisb A. Mother-to-infant and father-toinfant initial emotional involvement. Journal of Early Child Development and Care. 2007;177(5):521-32.

15. Bhakoo O, Pershad D, Mahajan R, Gambhir S. Development of mother infant attachment scale. Journal of Indian Pediatrics.1994;31:1477-82.

16. Figueiredo B. Bonding: understanding dimensions involved in initial maternal bonding with the infant. International Journal of Clinical and Health Psychology. 2003;3(3),521-39.

17. Mickelson M, Kristin D, Ronald C, Phillip R. Adult attachment in a nationally representative sample. Journal of Personality and Social Psychology. 1997;73(5):1106.

18. Scher A, Mayseless O. Mother of anxious lambivalent infants: Maternal characteristics and child-care context. Journal of Child Development. 2000;71(6):1629-39.

19. Mohamed N, Shaaban E, Ragheb M, Darwish A. Identify attachment behaviors among cesarean mothers. Alexandria Journal of Pediatrics. 1993;7(4):713-29.

20. Alhusen J. A Literature update on maternal-fetal attachment. Journal of Obstetric Gynecological Neonatal Nurse. 2008;37(3):315-28.

21. Cooper $P$, Tomlinson $M$, Swartz $L$. Improving quality of mother-infant relationship and infant attachment in 
socioeconomically deprived community in South Africa: A randomized controlled trial. BMJ. 2009;3(38):974.

22. Shaw D, Vondra J. Infant attachment security and maternal predictors of early behavior problems: A longitudinal study of low-income families. Journal of Abnormal Child Psychology. 1995;23(3):335-57.

23. Feldman R, Weller A, Leckman J, Kuint J, Eidelman $\mathrm{A}$. The nature of the mother's tie to her infant: maternal bonding under conditions of proximity, separation, and potential loss. Journal of Child Psychol Psychiatry. 1999;40(6):929-39.
24. Muller-Nix C, Forcada-Guex M, Jaunin L, Borghini A. Prematurity, maternal stress and mother-child interactions. Journal of Early Human Development. 2004;79:14558.

25. Pavard S, Sibert, A, Heyer E. The effect of maternal care on child survival: A demographic, genetic, and evolutionary perspective. Journal of Evolution. 2007;61:1153-61.

26. Gribble K. Mental health, attachment and breastfeeding: implications for adopted children and their mothers. International Breastfeeding Journal. 2006;1(5):1-5. 